\title{
The Impact of Short-term Combination of Limb Training and Pursed-lip Breathing in Chronic Obstructive Pulmonary Disease
}

\author{
Amira Permatasari Tarigan ${ }^{1 *}$, Fannie Rizki Ananda ${ }^{1}$, Pandiaman Pandia ${ }^{1}$, Trisno Susilo ${ }^{2}$, Maryaningsih Maryaningsih ${ }^{2}$, \\ Anggriani Anggriani ${ }^{2}$ \\ ${ }^{1}$ Department of Pulmonology and Respiratory Medicine, Faculty of Medicine, Universitas Sumatera Utara, Medan, Indonesia; \\ ${ }^{2}$ Division of Cardiorespiration, Faculty of Physiotherapy, STIKES Siti Hajar, Medan, Indonesia
}

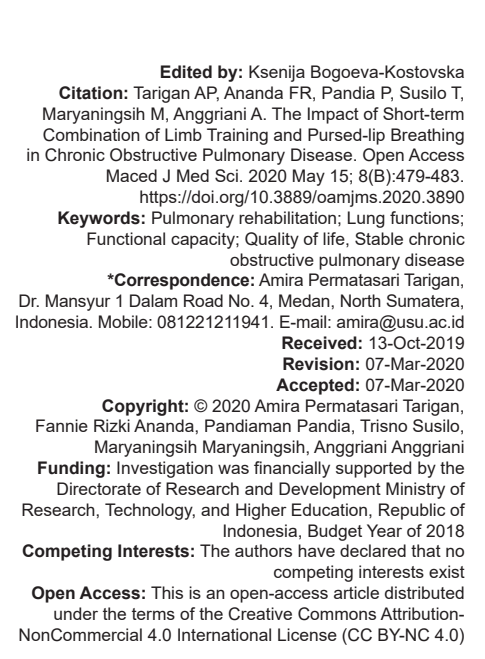

Abstract

AIM: The aim of this study is to determine the impact of short-term combination of upper and lower limb training on lung functions, functional capacity, and quality of life in stable chronic obstructive pulmonary disease (COPD).

METHODS: This quasi-experimental study held in 2017 and included 20 participants diagnosed with COPD (forced expiratory volume in 1 second/forced volume capacity $[F E V, / F V C] \leq 70 \%)$. Combination of limb training with pursedlip breathing held twice a week for 8 weeks. Lung functions, functional capacity, dyspnea scale, and quality of life were measured before, 1 month, and 2 months after training.

RESULTS: In this study, there was a significant improvement of FVC after 2 months after training (p-value: 0.04) but not in FEV. There was a significant improvement of CAT (p-value: 0.00 ) and modified medical research council (p-value: 0.04 ) after 1 month of training. There was a significant improvement of 6-min walking test mean after 2 months of training ( $p$-value: 0.00 ).

CONCLUSIONS: Short-term combination of limb training and pursed-lip breathing impacted positively on FVC functional capacity, dyspnea scale, and quality of life in patients with COPD, but not in FEV . $_{\text {. }}$.

\section{Introduction}

Chronic obstructive pulmonary disease (COPD) begins a challenging disease in physicians to control the incidence and progression [1]. It is usually underdiagnosed in the early stage, so the majority of patients usually ask for help after having significant impairment in daily life, particularly in Asia-Pacific region [2]. This make COPD burden in Asia is greater than in developed Western countries, measured by high mortality rate, years of life lost, and years that had spent with the disability [3].

Pulmonary rehabilitation (PR) has a significant role in the treatment of COPD (GOLD, 2018) [1]. Most studies showed significant improvement of lung functions, exercise capacity, and muscle strength lead to decrease dyspnea scale and improve quality of life in COPD after a short period of PR [4], [5]. A combination of PR and pharmacological treatment provides a better outcome in exercise capacity, health-related quality of life, and mental health rather than pharmacological alone [6], [7]. These facts made PR was considered to be part of comprehensive treatment in patients with the global initiative of lung disease (GOLD) criteria B, C, and Din GOLD consensus in 2018 [1]. However, another study showed that in mild obstruction severity in COPD, $\mathrm{PR}$ also gives a positive impact in improving exercise capacity and quality of life patients with COPD [8].

Exercise-related PR consists of a few type of training include endurance, strength, upper limb training, and breathing training [1]. A combination of endurance and strength training can give a better outcome in patients with COPD [9]. From a study in India, upper limb training can synchronize and coordinate accessory muscles during respiration so it can decrease the thoracoabdominal desynchronized in COPD patients. Later, it reduced dyspnea and increase lung function in moderate to severe COPD [10]. This is line with a study that showed significant improvement of lung function, functional capacity, and quality of life in patients with COPD [11]. In another study, lower limb exercise proved to increase lung functions, lower limb strength, and exercise performance lead to significantly improve quality of life in patients with COPD after regular limb training [12]. This is in line with another study in Indonesia that showed a significant improvement of 
lung functions and decrease dyspnea symptoms after 8 weeks of lower limb training [11].

According to those studies, we conclude that $\mathrm{PR}$ is a considerable therapy in COPD. In the other hand, there was no definite type of exercise that gives the greatest impact in COPD regarding the duration, intensity, and supervision of the training [13]. Based on the studies above, the authors interest to examine the short-term effect of simple upper and lower limb training on functional outcomes, dyspnea scale, and quality of life in stable COPD. The aim of this study is to determine the impact of a combination of upper and lower limb training with breathing maneuver on lung functions, functional capacity, and quality of life in patients with stable COPD.

\section{Materials and Methods}

\section{Study design}

This was a quasi-experimental study which carried out in Pulmonology and Respiratory Medicine Department, Universitas Sumatera Utara in 2017. All study protocols had been approved by the Ethics Committee of Faculty of Medicine in Universitas Sumatera Utara.

\section{Participants}

Sampling was carried out by consecutive sampling with total participants were 20 patients who matched inclusion criteria and had no exclusion criteria. The inclusion criteria were men with smoking history, age 40-80 years, and had not been involved in any exercise program for this 2-month period. The diagnosis of COPD was established by history, physical examination, then confirmed by a spirometer examination with forced expiratory volume in 1 second/forced volume capacity $\left(\mathrm{FEV}_{1} / \mathrm{FVC}\right) \leq 70 \%$. The exclusion criteria of this study were patient in exacerbation state, had severe musculoskeletal or neuromuscular disease, cardiovascular problem with NYHA $>1$, and attend the exercise program irregularly.

\section{Protocols}

After all, participants understood the content of the study and signed the informed consent, they were examined by a physician to make sure either they were clinically stable or not. If they were in a stable state, they were given short-acting bronchodilator (salbutamol two puffs) with spacer. Then, they commenced $15 \mathrm{~min}$ consisted of chest physiotherapy and muscle stretching, 10-15 min of upper limb training, and 5-20 min for lower limb training gradually increased.

Upper limb training was led by physiotherapist and video. It consisted of a few simple exercises using arms and shoulders with pursed-lip breathing and then cooled down. Lower limb training used stationary bicycle lasted 5-20 min gradually. These training programs held twice a week for 8 weeks. During the training program, physicians measured the vital sign and monitored participants' status of health. If there was an exacerbation state, the participants would get immediate treatments with oxygen.

The followings were measured before the training, 1 month after training, and 2 months after training:

1. Lung functions were measured with $F E V_{1}$ and FVC. GOLD grade was made based on $\mathrm{FEV}_{1}$ that divided into four categories. GOLD 1 for $\mathrm{FEV}_{1}>80 \%$, GOLD 2 for $\mathrm{FEV}_{1}$ 50-79\%, GOLD 3 for FEV, $30-49 \%$, and GOLD 4 for $\mathrm{FEV}_{1}<30 \%$ [1].

2. Dyspnea scale was measured with the modified medical research council (mMRC) which score $\geq 2$ means patients have severe dyspnea [1].

3. Functional capacity was measured by 6-min walking test (6MWT). Patients were instructed to walk as fast as they could for 6 min on the hospital corridor and decrease their speed if they experienced dyspnea or chest discomfort while the timer was not stopped [14]. In this study, the length track is $15 \mathrm{~m}$.

4. Quality of life measured by the COPD assessment test (CAT). CAT questionnaire shows the impact of COPD on patients' quality of life. The accumulative score $\geq 10$ interpreted the impaired of patients' quality of life [1].

\section{Statistical analysis}

All the collected data were entered and analyzed using Statistical Package for the Social Science for Windows version 16.0. Data were described in the distribution of frequencies then analyzed using paired $t$-test for bivariate analysis or Wilcoxon test if data were not normally distributed to determine the significant changes of lung functions, functional capacity, dyspnea scale, and quality of life from baseline to 1 month or 2 months after training. $p<0.05$ was considered significant.

\section{Results}

Twenty patients participated in this study with adequate compliance and had completed all sessions of upper and lower limb training.

From Table 1, we showed that the majority of the subject was aged 60-69 years old with Brinkman index severe ( $\geq 600)$. Based on GOLD 2018 [1], most patients were in group $D$ (high risk, more symptoms) with GOLD severity in Class III-IV (high risk), CAT score was $\geq 10$, and $m M R C$ scores was $\geq 2$ (more symptom). Mean of FVC in $44.8 \%$ which means the majority of patients 
Table 1: General characteristics of study and baseline value of lung function, functional capacity, dyspnea scale, and quality of life of population subject

\begin{tabular}{|c|c|c|c|}
\hline Characteristics & $n$ & $\%$ & Mean \pm SD \\
\hline Age (years old) & & & $64.45 \pm 5.3$ \\
\hline $40-49$ & 0 & 0 & \\
\hline $50-59$ & 4 & 20 & \\
\hline $60-69$ & 10 & 50 & \\
\hline $70-79$ & 6 & 30 & \\
\hline Brinkman index & & & $730.30 \pm 4.56$ \\
\hline Mild $(<200)$ & 1 & 5 & \\
\hline Moderate (200-599) & 8 & 40 & \\
\hline Severe $(\geq 600)$ & 11 & 55 & \\
\hline Group of patients & & & - \\
\hline A & 0 & 0 & \\
\hline B & 0 & 0 & \\
\hline C & 5 & 25 & \\
\hline D & 15 & 75 & \\
\hline GOLD severity $\left(\mathrm{FEV}_{1}\right)(\%)$ & & & $40.35 \pm 19.4$ \\
\hline $\mathrm{I}(\geq 80)$ & 2 & 10 & \\
\hline II $(50-70)$ & 4 & 20 & \\
\hline III $(30-49)$ & 7 & 35 & \\
\hline IV $(<30)$ & 7 & 35 & \\
\hline CAT score & & & $14.8 \pm 10.73$ \\
\hline$<10$ & 7 & 35 & \\
\hline$\geq 10$ & 13 & 65 & \\
\hline mMRC & & & $2 \pm 1.52$ \\
\hline $0-1$ & 9 & 45 & \\
\hline$\geq 2$ & 11 & 55 & \\
\hline FVC (\%) & & & $44.8 \pm 21.36$ \\
\hline 6MWT (m) & & & $297.65 \pm 38.49$ \\
\hline
\end{tabular}

were in a severe restrictive state. Mean of 6MWT test was 297.65 meters which classified in low class.

From Table 2, there was an improvement of FEV1 from baseline (mean: $40.35 \pm 19.4$ ) to 1 month after training (mean: $44.95 \pm 18.84$ ) and 2 months after training (mean: $43.10 \pm 17.84$ ). However, there was no significant change in the statistical analysis of $F E V_{1}$ after training (Table 3).

Table 2: Mean and standard deviation of each parameter

\begin{tabular}{llll}
\hline Parameters & \multicolumn{3}{l}{ Mean \pm SD } \\
\cline { 2 - 4 } & Baseline & 1 month training & 2 months training \\
\hline FEV & $40.35 \pm 19.94$ & $44.95 \pm 18.84$ & $43.10 \pm 17.84$ \\
FVC & $44.80 \pm 21.37$ & $53.70 \pm 18.35$ & $50.35 \pm 17.72$ \\
mMRC & $2.0 \pm 1.522$ & $1.40 \pm 1.188$ & $1.15 \pm 1.23$ \\
6MWT & $297.65 \pm 38.49$ & $302.45 \pm 47.99$ & $339.40 \pm 62.34$ \\
CAT & $14.8 \pm 10.7$ & $9.25 \pm 8.63$ & $10.8 \pm 8.24$ \\
\hline FEV : Forced expiratory volume in 1 second, mMRC: Modified medical research council, FVC: Forced \\
volume capacity, 6MWT: Six-minutes walking test, SD: Standard deviation.
\end{tabular}

volume capacity, 6MWT: Six-minutes walking test, SD: Standard deviation.

Based on Table 2, there was also the increased

of FVC from the base line (mean: $44.8 \pm 21.36$ ) to

1 month after training (mean: $53.7 \pm$ 18.39) and

2 months after training $(50.35 \pm 17.71)$. There was a significant change of FVC 2 months after training with $p<0.05$ in the paired $t$-test, but there was no significant change of FVC after 1 month, neither between 1 month and 2 months after training in statistical analysis.

Table 3: $p$-value of each observed parameters

\begin{tabular}{llll}
\hline Variables & $\begin{array}{l}\text { Baseline }-1 \text {-month } \\
\text { training }\end{array}$ & $\begin{array}{l}\text { Baseline }-2 \text { months } \\
\text { training }\end{array}$ & $\begin{array}{l}1 \text { month }-2 \\
\text { months training }\end{array}$ \\
\hline FEV ${ }_{1}$ & 0.20 & 0.42 & 0.67 \\
FVC & 0.10 & $0.04^{\mathrm{a}}$ & 0.38 \\
mMRC & $0.04^{\mathrm{a}}$ & 0.09 & 0.29 \\
$\mathrm{CAT}$ & $0.00^{\mathrm{a}}$ & $0.04^{\mathrm{a}}$ & 0.16 \\
6MWT & 0.58 & $0.00^{\mathrm{a}}$ & $0.00^{\mathrm{a}}$ \\
\hline Paired t-test was used to analyze $\mathrm{FEV}_{1}$ and FVC. Wilcoxon test was used to analyze mMRC, CAT, \\
and 6 MWT. *p-value was considered significant if <0.05. FEV F $_{1}$ : Forced expiratory volume in 1 second, \\
mMRC: Modified medical research council, FVC: Forced volume capacity, 6MWT: Six-minutes walking test.
\end{tabular}

Dyspnea scale was measured by the mMRC.

The results showed that mean value was decreasing between baseline and next 2 months after training. There was a significant change of mMRC mean between baseline and 1 month after training (Table 2) with $\mathrm{p}$ value $<0.05$ in Wilcoxon test, but not after 2 months of training (Table 3 ).

A functional capacity test was measured by 6 MWT. The results showed an increased mean from baseline to 1 month and 2 months after training. Further, in statistical analysis using Wilcoxon test, there was a significant change of means after 1 and 2 months of training compared with baseline with $p<0.05$ (Table 3).

Quality of life in patients with stable COPD measured by COPD assessment test (CAT) that showed a decreasing mean from baseline to 1 month and 2 months after the exercise program. There was a significant change of CAT mean in 1 month and 2 months after training with $p<0.05$ in Wilcoxon test (Table 3). However, there was no significant change between 1 month and 2 months after training.

\section{Discussion}

Upper and lower limb training is the main component of PR for stable COPD [15]. These programs contain endurance and strength component which give a good outcome for patients' physical activity and decrease dyspnea [16].

Limb training impacts on lung functions remain controversial in few studies [7], [9], [11], [12], [14], [16], [17], [18], [19], [20], [21], [22], [23], [24], [25], [26]. In this study, lung functions showed an increase if compared to baseline, although $\mathrm{FEV}_{1}$ was not significantly changed in statistical analysis. Few studies found that there was an improvement of lung functions after a short period of limb training, but it was not significant in statistical analysis [17], [18], [27]. These studies stated that short term of aerobic physical activity did not really modify lung functions. This might be because the destruction of airways in COPD is almost irreversible, so it is difficult for restoring and improving the lung function in COPD, especially in moderate to severe COPD patients [18]. However, when modifying with sitting calisthenics method for 3 months, a study showed a significant improvement of lung functions after upper and lower limb training [16]. Another study also found a significant improvement of lung functions after a short term of PR (6-8 weeks) in the supervised aerobic training group, but not in inspiratory muscle training and without supervised [28].

In this study, there was a significant improvement of FVC after 2 months of training compared with baseline and 1 month after training. These showed that combined upper and lower training could improve the lung vital capacity. Modifying limb training, particularly in upper limb training, could modify the ventilatory and postural muscles which impact in mechanical breathing of the ribcage and abdominal muscles compartment [20]. 
Limitation in doing a physical activity using the upper and lower limb is one of the main complaints in COPD patients [29]. An objective assessment of the functional capacity in this study was the 6MWT test with minimum increase track length which considered clinically significant is $50 \mathrm{~m}$ after PR [7]. British thoracic society (BTS) recommends a minimum increase which considered clinically significant is $54 \mathrm{~m}$ [30]. In this study, there was an increase of mean about $4.8 \mathrm{~m}$ after 1 month of training (297.65 $\pm 38.49-302.45 \pm 47.99)$, and $41,75 \mathrm{~m}$ after 2 months of training (297.65 $\pm 38.49-339.4 \pm 62.34)$. Although it was not considered significant according to the meta-analysis study and BTS recommendation, it was significant in statistical analysis using Wilcoxon test. This is in line with few studies. A study in Egypt stated that there was a significant difference of 6 MWT in moderatesevere COPD after 4 weeks of upper and lower limb training [18]. Another study found that PR for 8-12 weeks can improve the functional capacity not only for moderate to severe COPD but also in all grades of COPD [31]. Another study also found an increase about $59 \mathrm{~m}$ of 6MWT after 6 weeks of PR in COPD patients [32].

Dyspnea effect after PR may vary among individual, depend on GOLD grade and the duration of training. In this study, dyspnea scale had been decreased in patients after 1 month of training programs. This is in line with the few studies that showed a dyspnea decrease after short-term limb training [31], [33]. A meta-analysis study stated that short term of PR gives a greater impact for reducing dyspnea compare with long duration of PR [22]. There are four mechanisms describing the impact of limb training in dyspnea and all these mechanisms correlate each other. These mechanisms include changing in cardiovascular factors such as improving maximal oxygen uptake while exercise, decreasing ventilatory demand by increasing aerobic capacity, reducing neuromuscular decoupling by increasing inspiratory effort, end-expiratory-lung-volume, and respiratory rate. The last mechanism is exercise improve the breathing pattern such as slowing respiratory rate and decrease diaphragm and accessory muscle used [33].

Quality of life which measured by CAT questionnaire showed improvement after 2 months of the limb training. There has been several studies that stated limb training program has been associated with the improvement of quality of life in COPD, one of those were a study in Brazil with combined limb training in COPD patients that showed significant improvement of quality of life after 12 weeks of training [33]. Tarigan et al. also found a significant improvement of quality of life after 8 weeks of the upper limb training program [11]. A study in Japan stated that PR could ameliorate symptoms and increase exercise tolerance that leads to improve quality of life [27]. Lei Pan's study also found a significant improvement in health-related quality because it decreases dyspnea, improves muscle endurance and strength, so patients with COPD are able to do their daily activities as usual or with mild limitations [22]. Further, another study stated that PR could improve the psychological effect, included motivation and decreased anxiety or fear to exercise [10].

There are some limitations of this study. For the rehabilitation program, a larger group of participants and the need of a control group were needed to decrease host internal factor which can interfere the result of the study. Further, the track length which used to measure 6 MWT is usually $30 \mathrm{~m}$, or in 20-50 m range. However, due to the limitation in our hospital corridor, we just used $15 \mathrm{~m}$ track length.

\section{Conclusions}

From this study, we can conclude that shortterm combination of upper and lower limb training with pursed-lip breathing improved the functional capacity, dyspnea scale, and quality of life in patients with COPD.

\section{References}

1. Global Initiative for Chronic Obstructive Lung Disease Globa Strategy for the Diagnosis, Management, and Prevention of Chronic Obstructive Pulmonary Disease 2018 Report; 2018. Available from: http://www.goldcopd.org. https://doi.org/10.108 0/15412555.2017.1394285. [Last assessed on 2019 Oct 10].

2. Lim S, Lam DC, Muttalif AR, Yunus F, Wongtim S, Shetty V, et al. Impact of chronic obstructive pulmonary disease (COPD) in the Asia-Pacific region: The EPIC Asia population-based survey. Asia Pac Fam Med. 2015;14(1):4. https://doi.org/10.1186/ s12930-015-0020-9

PMid:25937817

3. Tan WC, Ng TP. COPD in Asia: where East meets West. Chest. 2008;133(2):517-27.

PMid:18252918

4. Ngaage DL, Hasney K, Cowen ME. The functional impact of an individualized, graded, outpatient pulmonary rehabilitation in end-stage chronic obstructive pulmonary disease. Heart Lung. 2004;33(6):381-9. https://doi.org/10.1016/j.hrtlng.2004.08.003 PMid:15597292

5. Ergün P, Kaymaz D, Günay E, Erdoğan $Y$, Turay ÜY, Demir N et al. Comprehensive out-patient pulmonary rehabilitation: Treatment outcomes in early and late stages of chronic obstructive pulmonary disease. Ann Thorac Med. 2011;6(2):70. https://doi.org/10.4103/1817-1737.78420

PMid:21572695

6. Canadian Agency for Drugs and Technologies in Health (CADTH). Pulmonary rehabilitation for chronic obstructive pulmonary disease: Clinical, economic, and budget impact analysis. CADTH Technol Overv. 2010;1(4):e0127. PMid:22977417

7. McCarthy B, Casey D, Devane D, Murphy K, Murphy E, Lacasse Y. Pulmonary rehabilitation for chronic obstructive pulmonary disease. Cochrane Database Syst Rev. 2006;4:1. https://doi.org/10.1002/14651858.cd003793.pub3

8. Jácome $\mathrm{C}$, Marques A. Pulmonary rehabilitation for mild COPD A systematic review. Respir Care. 2014;59(4):588-94. https:// 
doi.org/10.4187/respcare.02742

\section{PMid:24106321}

9. Ortega F, Toral J, Cejudo P, Villagomez R, Sánchez H, Castillo J, et al. Comparison of effects of strength and endurance training in patients with chronic obstructive pulmonary disease. Am J Respir Crit Care Med. 2002;166(5):669-74. https://doi. org/10.1164/rccm.2107081

PMid:12204863

10. Subin VR, Rao V, Prem V. Effect of upper limb, lower limb and combined training on health-related quality of life in COPD. Lung India. 2010;27(1):4-7. https://doi. org/10.4103/0970-2113.59260

PMid:20539763

11. Tarigan AP, Ananda FR, Pandia P, Sinaga BY, Maryaningsih M, Anggriani $A$. The impact of upper limb training with breathing maneuver in lung function, functional capacity, dyspnea scale, and quality of life in patient with stable chronic obstructive of lung disease. Open Access Maced J Med Sci. 2019;7(4):567-72. https://doi.org/10.3889/oamjms.2019.113

PMid:30894913

12. Walker PP, Burnett A, Flavahan PW, Calverley PM. Lower limb activity and its determinants in COPD. Thorax. 2008;63(8):6839. https://doi.org/10.1136/thx.2007.087130 PMid: 18487318

13. Santus P, Bassi L, Radovanovic D, Airoldi A, Raccanelli R, Triscari F, et al. Pulmonary rehabilitation in COPD: A reappraisal (2008-2012). Pulm Med. 2013;2013:374283. https://doi. org/10.1155/2013/374283

14. ATS Committee on Proficiency Standards for Clinical Pulmonary Function Laboratories. ATS statement: Guidelines for the sixminute walk test. Am J Respir Crit Care Med. 2002;166(1):111-7. https://doi.org/10.1164/ajrccm.166.1.at1102 PMid:12091180

15. Sharma BB, Singh V. Pulmonary rehabilitation: An overview. Lung India. 2011;28(4):276. PMid:22084542

16. Takahashi $H$, Sugawara $K$, Satake $M$, Shioya $T$, Kagaya $H$, Kawatani M. Effects of low-intensity exercise training (chronic obstructive pulmonary disease sitting calisthenics) in patients with stable chronic obstructive pulmonary disease. Jpn J Compr Rehabil Sci. 2011;2:5-12. https://doi.org/10.1016/j.rmed.2015.01.008

17. Lan CC, Chu WH, Yang MC, Lee CH, Wu YK, Wu CP. Benefits of pulmonary rehabilitation in patients with COPD and normal exercise capacity. Respir Care. 2013;58(9):1482-8. https://doi. org/10.4187/respcare.02051

PMid:23287013

18. Elmorsy AS, Mansour AE, Okasha AE. Effect of upper limb, lower limb and combined training on exercise performance, quality of life and survival in COPD. Egypt $\mathrm{J}$ Chest Dis Tuberc. 2012;61(3):89-93. https://doi.org/10.1016/j.ejcdt.2012.10.008

19. McKeough ZJ, Velloso M, Lima VP, Alison JA. Upper limb exercise training for COPD. Cochrane Database Syst Rev. 2016;11:CD011434. https://doi.org/10.1002/14651858.cd011434. pub2

PMid:27846347

20. Criner GJ, Celli BR. Effect of unsupported arm exercise on ventilatory muscle recruitment in patients with severe chronic airflow obstruction. Am Rev Respir Dis. 1988;138(4):856-61. https://doi.org/10.1164/ajrccm/138.4.856 PMid:3202459

21. Nici L, Donner C, Wouters E, Zuwallack R, Ambrosino N Bourbeau J, Carone M, et al. American thoracic society/European respiratory society statement on pulmonary rehabilitation. Am J Respir Crit Care Med. 2006;173(12):1390-413. https://doi. org/10.1164/rccm.200508-1211 ${ }^{\text {st }}$

\section{PMid: 16760357}

22. Pan L, Guo YZ, Yan JH, Zhang WX, Sun J, Li BW. Does upper extremity exercise improve dyspnea in patients with COPD? A meta-analysis. Respir Med. 2012;106(11):1517-25. https://doi. org/10.1016/j.rmed.2012.08.002

PMid:22902265

23. Dourado VZ, Tanni SE, Antunes LC, Paiva SA, Campana AO, Renno AC, et al. Effect of three exercise programs on patients with chronic obstructive pulmonary disease. Braz $J$ Med Biol Res. 2009;42(3):263-71. https://doi.org/10.1590/ s0100-879 × 2009000300007

PMid: 19287905

24. Hsieh MJ, Lan CC, Chen NH, Huang CC, Wu YK, Cho HY, et al. Effects of high-intensity exercise training in a pulmonary rehabilitation programme for patients with chronic obstructive pulmonary disease. Respirology. 2007;12(3):381-8. https://doi. org/10.1111/j.1440-1843.2007.01077.x

PMid: 17539842

25. Tarigan AP, Pandia P, Mutiara E, Pradana A, Rhinsilva E, Efriyand E. Impact of lower-limb endurance training on dyspnea and lung functions in patients with COPD. Open Access Maced J Med Sci. 2018;6(12):2354-58. https://doi.org/10.3889/oamjms.2018.381 PMid:30607190

26. Singh VP, Jani H, John V, Singh P, Joseley T. Effects of upper body resistance training on pulmonary functions in sedentary male smokers. Lung India. 2011;28(3):169-73. https://doi. org/10.4103/0970-2113.83971

\section{PMid:21886949}

27. Yoshimi K, Ueki J, Seyama K, Takizawa M, Yamaguchi S, Kitahara $\mathrm{E}$, et al. Pulmonary rehabilitation program including respiratory conditioning for chronic obstructive pulmonary disease (COPD): Improved hyperinflation and expiratory flow during tidal breathing. J Thorac Dis. 2012;4(3):259-64. https:// doi.org/10.2147/copd.s30399 PMid:22754664

28. Saey D, Bernard S, Gagnon P, Laviolette L, Soicher J, Maltais F, et al. Pulmonary Rehabilitation in Chronic Obstructive Pulmonary Disease. Panminerva Med. 2009;51(2):95-114. https://doi. org/10.1164/ajrccm-conference.2009.179.1_meetingabstracts. a1048

PMid: 19776711

29. Costa D, Cancelliero KM, Ike D, Laranjeira TL, Pantoni CB, Borghi-Silva A. Strategy for respiratory exercise pattern associated with upper limb movements in COPD patients. Clinics (Sao Paulo). 2011;66(2):299-305. https://doi.org/10.1590/ s1807-59322011000200020 PMid:21484050

30. Dodd JW, Hogg L, Nolan J, Jefford H, Grant A, Lord VM, et al. The COPD assessment test (CAT): Response to pulmonary rehabilitation. A multicentre, prospective study. Thorax. 2011;66(5):425-9. https://doi.org/10.1136/thx.2010.156372 PMid:21398686

31. Alfarroba S, Rodrigues F, Papoila AL, Santos AF, Morais L. Pulmonary rehabilitation in COPD according to global initiative for chronic obstructive lung disease categories. Respir Care. 2016;61(10):1331-40. https://doi.org/10.4187/respcare.04414 PMid:27407179

32. Finnerty JP, Keeping I, Bullough I, Jones J. The effectiveness of outpatient pulmonary rehabilitation in chronic lung disease: A randomized controlled trial. Chest. 2001;119(6):1705-10. https://doi.org/10.1378/chest.119.6.1705 PMid:11399694

33. Stendardi L, Binazzi B, Scano G. Exercise dyspnea in patients with COPD. Int J Chronic Obstruct Pulmon Dis. 2007;2(4):429. PMid:18268917 